\title{
DOCUMENTOS INÉDITOS SOBRE EL FAMOSO PLEITO DE LOS PINTORES: EL LARGO CAMINO RECORRIDO POR LOS ARTISTAS DEL SIGLO XVII PARA EL RECONOCIMIENTO DE SU ARTE COMO LIBERAL
}

\author{
POR \\ Juan Antonio Díez-Monsalve Giménez y Susana Fernández de Miguel \\ Universidad de Málaga
}

\begin{abstract}
El reconocimiento de la pintura como arte liberal no fue el resultado de una sola batalla, sino el final de un largo camino de lucha recorrido por los pintores en defensa de la dignidad de su arte, que tuvo su punto álgido en los diversos litigios que tuvieron que mantener frente a la Hacienda del Reino, cuando pretendió exigirles el pago de los mismos impuestos que a los demás artesanos y comerciantes. Los pintores se rebelaron y decidieron defenderse frente a lo que estimaron un agravio a la nobleza de la pintura y a su identidad como artistas. En esta lucha estuvieron apoyados por los intelectuales de la época y sobre todo por un Rey, reconocido mecenas y amante y practicante de la pintura.
\end{abstract}

Palabras clave: Gremio; Pintores; Alcabala; Ordenanza.

The recognition of painting as a liberal art was not the result of a single battle, but the conclusion of a long struggle by painters to defend the dignity of their art. This conflict reached its high point in the various lawsuits they undertook against the Royal Treasury, when an attempt was made to demand the same tax payments from artists as from mere artisans and tradesmen. The painters rebelled and decided to defend themselves against what they considered to be an insult to the nobility of painting and their identity as artists. In this dispute they found support in the intellectuals of their time and especially in the King, a recognized patron of artists and connoisseur of painting, as well as a practicing painter.

Key words: Guild; Painters; Sales tax; Ordinance.

Durante el primer cuarto del siglo XVII, los desequilibrios entre ingresos y gastos en la Real Hacienda, que culminaron con la bancarrota declarada por Decreto el 31 de Enero de 1627, originaron una creciente presión recaudatoria desde la Corona, que trajo consigo una serie de movimientos antifiscales desde diversos sectores de la población. 
Entre estos movimientos destacó, por su relevancia, el de los pintores, que se alzaron frente a la Hacienda Real por la imposición de la alcabala a la venta de las pinturas, actividad que, hasta ese momento, no había estado sujeta al pago del impuesto.

La importancia y fortaleza de la rebelión de los pintores radicó en que no sólo tuvo una motivación de origen impositivo, sino la decidida pretensión de la equiparación de la pintura a las demás artes liberales y su distanciamiento de las mecánicas, basada en la certeza de integrar su oficio una actividad intelectual, y la obtención del reconocimiento social inherente.

Nuestra investigación ha arrojado la constatación de que el famoso Pleito de los Pintores no fue un hecho aislado del que se obtuviera el resultado ya conocido. Por el contrario, la consecución de la introducción del calificativo artístico al resultado de la actividad pictórica, frente al mecanicismo de los demás oficios, fue el resultado de una larga peregrinación a través de casi una década, como constatamos a través de los documentos inéditos obtenidos y que fue pareja a la lucha en favor de la exención impositiva de su oficio, al estimar los pintores que no debían estar sujetos a ninguna carga impositiva que gravara la creación de sus obras.

La primera escaramuza de esta larga batalla se inició el 28 de febrero de 1623, fecha en que el Gremio de los Pintores y Doradores compareció ante el escribano real, representados por Sebastián de Mora y Julio de la Peña, para otorgar poder en favor de los Procuradores de la Real Chancillería, Fernando Belardes y Xpoul de Cafra, para que, en su nombre, siguieran un pleito que se encontraba en la Sala de Alcaldes de los Hijosdalgo de la Hacienda y el Alcavalera de la Villa de Madrid, sobre los pagos debidos por los pintores durante los años 1621 y 1622, por el que pretendían que se pagara el Alcavala de Pinturas y quadros de santos y figuras dibinas ${ }^{1}$.

La exigibilidad del pago de la alcabala a los pintores en ese momento era consecuencia de la reclamación del Rey y, por su orden, de los ministros del pago del uno por ciento a los pintores por la venta de las pinturas, como se realizaba a los demás comerciantes.

En plena contienda judicial y a efectos de las probanzas necesarias, Juan Belázquez, pintor, por sí y en nombre del Gremio de los pintores de Madrid, compareció el 2 de noviembre de 1623 ante el escribano Pedro Gutiérrez, solicitando que se recibiera información de testigos, a fin de probar que tanto a los pintores, como a los escultores, no se les había cobrado nunca el impuesto reclamado, ni nunca lo habían pagado ${ }^{2}$.

Ese mismo día se proveyó la información y el día 8 siguiente, el mismo Juan Belázquez presentó a Diego Velázquez, Pintor del Rey, como testigo, quien tras declararse de la edad de veintiocho años, manifestó que, después que su Majestad mandara cobrar el uno por ciento de lo que se bendiese, los cobradores habían acudido a los pintores de la Corte para cobrar este impuesto y éstos se habían defendido, no pagando lo reclamado y acudiendo al rey para que $l o$ remediase.

Dentro de la información, Diego Velázquez testificó que los pintores no habían pagado el impuesto por las pinturas que vendían y que habían quedado por ello exentos de su pago, a diferencia de los demás oficios que sí lo habían pagado, por gravar todas aquéllas cosas que estaban dentro del comercio y firmando seguidamente, de su puño y letra, la declaración ${ }^{3}$.

El día 16 de noviembre siguiente, el mismo Juan Belázquez presentó a Ángelo Nardi, pintor del Rey, quien también prestó juramento en el mismo sentido.

Nardi, que confesó ser de cincuenta y nueve años, más o menos, aclaró que los arrendadores estaban exigiendo a los pintores el pago del impuesto como a todos los mercaderes, por los géneros vendidos, por considerar a las pinturas como objetos dentro del comercio y para el consumo

\footnotetext{
1 AHPM: Tomo 5055, 28 febrero 1623, fls.: 39-39 vto.

2 AHPM, Protocolo 3950, fl. 1346.

3 Ibid., fl. 1348
} 
y por lo tanto sujetas al mismo ${ }^{4}$. Refiere, además, que los pintores de la Corte habían acudido a su Majestad solicitándole que no se les exigiera el impuesto sobre lo que ellos vendieran y que, como consecuencia de esta petición, los arrendadores había cesado en su exigencia y no habían cobrado el impuesto.

Por último, ese mismo día, Juan de Belázquez presentó a Francisco Janete ${ }^{5}$, Pintor de su Alteza el Infante $\mathrm{Cardenal}^{6}$, quien manifestó ser de cincuenta y dos años, declarando, en el mismo sentido que los anteriores y que, ante el requerimiento de pago del uno por ciento de lo vendido efectuado desde la Corona, los pintores se habían negado defendiendo que no estaban obligados a ello y haber acudido al Rey solicitando que no lo cobrasen, por lo que los Recaudadores habían cejado en el cobro y a realizar en adelante diligencia alguna contra los pintores ${ }^{7}$.

En suma, los tres pintores más importantes del momento, los dos Pintores del Rey y el Pintor del Infante Cardenal, testimoniaron, al serles reclamado el impuesto, que habían acudido a su Majestad para que éste declarara que los pintores no estaban sujetos al pago de la alcabala del uno por ciento en la venta de sus pinturas.

A estos testimonios se añadió la información instada, en la villa de Madrid, a finales de 1627, por el pintor Andrés Carreño, vecino de la ciudad de Valladolid, quien compareció por sí y en nombre de los demás pintores y además como Alcalde de la Cofradía del glorioso San Lucas, Patrón del dicho arte ${ }^{8}$, para probar con testigos que el Recaudador del uno por ciento había citado a algunos de los pintores, requiriéndoles para el pago del impuesto y que éste no había proseguido en la reclamación por haber acudido el arte de la pintura, es decir el Gremio de los pintores en bloque, a su Majestad y dado memorial, explicando los motivos por los que consideraban estar exentos del pago de dicho impuesto y solicitando que, estando vigentes esas causas, debía resolverse en favor del dicho arte y así se había hecho, sobreseyéndose, en consecuencia, la pretensión del arrendador.

El 4 de febrero de 1628, compareció, como testigo de esta información, el pintor Antonio de Monreal $^{9}$, manifestando que, por lo que se refería a los pintores residentes en Madrid, era público y notorio que los pintores de la Corte no habían pagado el uno por ciento en ningún momento.

Continuaba la información con la comparecencia, el día 5 de febrero siguiente, del pintor Jacinto Carbonel, Aparejador Mayor de las Obras de su Majestad y Maestro Mayor del Alcázar ${ }^{10}$, y bajo juramento reiteró que los pintores habían dado memorial a su Majestad, mencionando que la exigencia del impuesto del uno por ciento se había extendido también a los escultores de la Corte.

Hay otros testimonios en esta información, entre los que destaca el prestado por Don Fernando de la Hoz, Gentilhombre de la Casa del Rey, quien, juramentado en forma, afirmó conocer también que los pintores habían dado memorial a su Majestad, hablándole de las razones por las que consideraban noble y liberal al arte de la pintura y que por ello debía tenérsela por libre del pago de toda contribución ${ }^{11}$. Refirió, asimismo, que los pintores fundamentaron su petición en las

${ }^{4}$ Ibid., fl. 1347.

5 JANETE: apellido españolizado de Janette, conocido como pintor inglés de retratos del siglo XVII. Este artista es citado por Siret como ayant fait un Portrait de Marie Stuart, reine d'Ecosse, que se conserva en el Museo Británico en Londres. No se conserva ninguna biografía inglesa del pintor, pero de su reconocimiento dice el haber sido retratista de personajes reales de su tiempo. Se trataría, pues, esta información de un documento muy importante para el seguimiento biográfico y artístico del pintor.

${ }^{6}$ Don Fernando, hijo del rey Felipe III y hermano de Felipe IV. Nació en El Escorial, en 1609. El infante nunca fue ordenado sacerdote, aunque en 1619, fue nombrado arzobispo de Toledo.

${ }^{7}$ AHPM, op. cit. nota 2, fl. 1347 vto.

8 AHPM: Protocolo 5927, fl. 170.

9 Ibid., fl. 171.

${ }^{10}$ Ibid., fl. 171 vto.

11 Ibid., fl. 172. 
leyes antiguas de los emperadores, por las que éstos habían favorecido y eximido a los profesores de dicho arte de todas las gabelas con las que contribuían el resto de sus súbditos y que, no contentos con ello y, por considerar a la pintura como la más noble de todas las artes, la habían ejercitado con sus propias manos, como lo había hecho también el propio Rey Felipe IV.

Lo más interesante que arroja este testimonio es la constatación de que la exención del pago del uno por ciento a los pintores, no se produjo nunca por una orden expresa del Rey, sino por una recomendación verbal de éste, ante la que los recaudadores y arrendadores habían desistido de su reclamación, pero sin formalizarla expresamente, simplemente abandonando el proceso en el estado en que se encontraba.

Otros de los testimonios corresponden a Antonio $\mathrm{Araoz}^{12}$, que manifestó ser vecino de Madrid, y a don Gerónimo Sunesta y Muñoz, Caballero de la Orden de Santiago y de su Consejo y del Consejo Supremo de la Villa y su Conservador General ${ }^{13}$, declarando ser muy aficionado a la pintura y maravillarse de que se pudiera yntentar cosa semejante. En su testimonio citó a la pintura como arte muy noble, privilegiada y estimada de los emperadores y reyes y terminó aludiendo al memorial dado por los pintores a su Majestad, obteniendo por ello mención en su favor, que motivó que, en adelante, no se les molestara en el cobro del uno por ciento.

El último de ellos pertenece a Juan Gómez de Mora, Trabador y Maestro Mayor de las Obras de su Majestad, quien manifestó, además de lo general, conocer que los pintores de la Corte no habían pagado derecho alguno, tanto moderno como antiguo, y que, ante la reclamación del uno por ciento a los pintores por las ventas de sus obras, en Madrid, Vicente Carducho, en representación de los pintores había dado un memorial a su Majestad, presentando las causas por las que solicitaban que se les eximiera del pago de este impuesto, mencionando que estas razones hacían referencia a que a los pintores siempre se les había reconocido las mismas exenciones y privilegios que a las demás artes liberales, considerando que el arte de la pintura era noble y menester del esfuerzo divino y que sólo era alcanzado a fuerza del estado de ingenio, razón por la que había sido estimada en todo mundo y honrados sus profesores tanto en Italia, como por los Reyes de Castilla ${ }^{14}$.

La mayor parte de los testimonios hicieron referencia a un memorial y cabe preguntarse a qué memorial se referían los pintores en sus informaciones.

Hoy estamos en condiciones de dar cumplida satisfacción a esta pregunta. El memorial existe y se conserva en la Biblioteca Nacional. Este memorial fue publicado por Cruzada Villaamil en 1866, en un artículo titulado Conatos de formar una academia o escuela de dibujo en Madrid en el siglo XVII, en el que daba noticia del hallazgo de un memorial que trataba de la defensa del arte de la pintura y de las normas o estatutos para la creación de una Academia ${ }^{15}$ y recogido, posteriormente, por Francisco Calvo Serraller en su obra Teoría de la Pintura del Siglo de Oro ${ }^{16}$.

Ambas publicaciones hacían referencia a un Impreso sin fecha ni lugar que se conserva en la Biblioteca Nacional de Madrid, como anónimo y posiblemente datado, incluyéndose con interrogaciones la fecha de 1619.

Nuestra búsqueda en los fondos antiguos de la Biblioteca Nacional ha dado como fruto la localización de este Memorial incorporado a un tomo en el que consta la fecha exacta de su presentación ante su Majestad. El Memorial se contiene en un tomo titulado Sucesos del año $1619^{17}$.

12 Ibid., fl. 174

13 Ibid., fl. 175.

${ }^{14}$ Ibid., fl. 175 vto.

15 Cruzada Villaamil, G.: "Conatos de formar una academia o escuela de dibujo en Madrid en el siglo XVII", El Arte en España, núm. 132. 1866, pp. 167 y ss.

${ }^{16}$ Calvo Serraller, F.: Teoría de la Pintura del Siglo de Oro. Ediciones Cátedra. Madrid 1991, pp. 157-177.

17 BNE, Microfilm 10.600: Sucesos del año 1619: Este memorial sedio al Rei don Felipe 3. ${ }^{\circ}$, p. 272. 
Este tomo se inicia con un Índice de las cosas contenidas en este tomo intitulado "Sucesos del año 1619” y, en su página 232, aparece el documento con el siguiente encabezamiento: Este memorial sedio al Rei don Felippe 3. ${ }^{\circ}$

Calvo Serraller señaló a Vicente Carducho como probable autor del Memorial como se demuestra en anotaciones a pié de página que acompañan a nuestra publicación del indicado texto, varios de sus fragmentos son reproducidos literalmente en los Diálogos.

La datación del Memorial permite mantener una tesis contraria. Si el Memorial se presentó ante el Rey Felipe III en 1619 y Carducho publica su obra en 1633, tenemos que afirmar que el primero es bastante anterior y que por ello no necesariamente lo tuvo que confeccionar Vicente Carducho, a la vista del número de personajes ilustres y pintores que apoyaron la medida. Tampoco debemos olvidar los numerosos tratados coetáneos que trataron de ensalzar a la pintura y elevarla al rango de las artes liberales, que acreditan haber sido una reivindicación anterior a la obra de Carducho.

Así Jusepe Martínez, pintor aragonés, fue uno de los primeros autores en España en propugnar la igualdad de la pintura a las otras artes liberales. Dedicó parte de su obra a la crítica de arte y en su libro Discursos practicables del nobilisimo arte de la pintura ${ }^{18}$, se confiesa defensor del reconocimiento y estimación del arte del dibujo y la pintura, a la que coloca en lo más elevado de las artes liberales, pronunciándose en la siguiente forma

"Es la pintura un liberal ejercicio, que con el arte pretende imitar a la naturaleza...

Su cumbre es esprimir lo vigoroso, y bello difundiendo en toda la jurisdicción de lo visible este arte las leyes de que parezcan con belleza; bien se colige pues, ser noble la facultad; que la hermosura contempla, por ser ésta madre del amor, por cuyo tenor se desprenden de su altivez las puntas de las diademas apasionada y contrapuntadas de su harpón; el modo de ejercerse no es menos que divinizado, porque la idea del pintor, no por su eje efigie, sino por otra como movida del furor divino la significa en sus delineaciones, muy apartada de lo mecánico..."

Don Juan de Austria, a quien dedica su libro, le contestó en la siguiente forma

"Al estudioso Amador de la pintura: Muchos son los motivos que los escriptores han tomado para sacar a la luz sus conceptos; y aunque diferentes unos de otros, siempre ha sido el preciso y más loable el dejar doctrina, avisos y enseñanza en beneficio de los venideros."

De estas citas se deduce claramente cómo ya, en la sociedad del momento, se comenzaba a consolidar la consideración del pintor como artista.

En 1633, Antonio de León Pinelo ${ }^{19}$, reconocido jurista y Relator del Consejo de Indias, en un estudio doctrinal que seguramente le habrían encargado los pintores, mantuvo que la Pintura, en sus lienzos y tablas, por tiempo y costumbre inmemorial, goza legítimamente esta exempción, se refería al pago de alcabalas, por lo que luego tiénela prescripta, es decir, consideraba que la exigibilidad de la alcabala sobre las pinturas había prescrito al no haberse cobrado este impuesto desde tiempo inmemorial.

\footnotetext{
18 Martínez, J.: Discursos practicables del nobilísimo arte de la Pintura, sus rudimentos, medios y fines que enseña la experiencia, con los ejemplares de obras insignes de artifices ilustres, por Jusepe Martínez, pintor de S. M. D. Felipe IV, y del SERMO. SR. D. Juan de Austria, a quien dedica esta obra. Notas, vida del autor y reseña histórica de la pintura en la Corona de Aragón por Valentín Carderera y Solano. Madrid, Real Academia de San Fernando, 1866.

19 LeÓn Pinelo, A. de: "Por la Pintura y su exempcion de pagar alcabalas". En: CARducho, V., Apéndice a los Diálogos de la Pintura. Gregorio Cruzada Villamil. 2. ${ }^{a}$ Edición. Madrid, Impr. de M. Galiano, 1865, pp. 379-402. Disponible en web: http://books.google.es/books?id=kTUtAAAAYAAJ\&printsec=titlepage.
} 
Como antecedentes a estos tratados, en 1605, el Padre Fray José de Sigüenza, uno de los primeros críticos de arte en España, en su obra Tercera parte de la historia de la Orden de San Gerónimo, Doctor de la Iglesia, dedicó su Discurso XVII a la grandeza y variedad de la pintura que se contiene en el Escorial ${ }^{20}$ y en 1606 se había creado, en Madrid, la Academia del Arte de la Pintura de San Lucas ${ }^{21}$, que se situó en el Convento de nuestra Señora de la Victoria.

Juan de Jáuregui, uno de los primeros poetas de su época y también pintor, había dedicado parte de sus composiciones poéticas a las artes plásticas, lo que evidenciaba su preocupación teórica por el arte de la pintura. En 1618, este mismo autor había publicado, en Sevilla, su obra Diálogo entre la naturaleza y las dos artes, pintura y escultura, de cuya preminencia se disputa y juzga. Dedicado a los prácticos y teóricos en estas artes ${ }^{22}$.

Posteriores son las publicaciones de Juan de Butrón, profesor en ambos derechos y abogado del Consejo de Castilla, quien en 1626 publicó Discursos apologéticos en que se defiende la ingenuidad del arte de la pintura, que es liberal y noble de todos los derechos ${ }^{23}$.

De este autor nos interesan dos citas concretas contenidas en la Epístola dirigida al Rey suplicando protección para la Academia de los Pintores ${ }^{24}$. En la primera hace referencia a la existencia de varios episodios liquidatorios impositivos por los que los Recaudadores solicitaron impuestos a los pintores, refiriendo que Largamente, señor, provaron su nobleza y exempciones en los discursos que con este a V. M. presentan (de quienes estos pliegos son epílogo). En la segunda Suplica a V. M. humildemente atienda a sus razones, y no niegue el oído a sus vozes; pues por tantos títulos tienen grangeado vuestro afecto, ya sirviendo con su arte, ya enseñando a V. Magestad su conocimiento.

Estos escritos también pudieron tener su origen en un encargo expreso de los pintores, dado que Butrón asumió la defensa de la apelación contra una primera sentencia del pleito que Vicente Carducho promovió contra los Recaudadores de las alcabalas, en su nombre y en el de los demás pintores.

El licenciado Gaspar Gutiérrez de los Ríos, profesor de ambos Derechos y Letras humanas, publicó en 1660 un estudio sobre la naturaleza jurídica del impuesto de la alcabala, titulado Notizia general para la estimación de las artes ${ }^{25}$, centrándose en si su naturaleza era compatible o no con la prescripción, fundamentando la compatibilidad de ambas figuras jurídicas, opinión que fue, a su vez, rebatida por el Fiscal del Consejo del Rey.

Lorenzo van der Hamen, Capellán de los Naturales, Congregación de los sacerdotes jubilados de la Corte, y posterior vicario de Yuvides, declaró en la misma ocasión saber que los pintores no habían sido incluidos en repartimiento alguno hecho en estos Reinos, por lo que se debían considerar libres por los privilegios que los Reyes de España les habían concedido a imitación de los demás Príncipes de Europa y que tampoco habían pagado alcabala por pintura alguna, propia o ajena ${ }^{26}$.

En defensa de la liberalidad de la pintura publicaron también textos Lope de Vega, José de Valdivieso y Juan Rodríguez de León, aunque desde un punto de vista más literario que científico ${ }^{27}$.

Todos estos escritos, testimonios y tratados crearon el clima apropiado para que la creación del memorial fuera fruto de una voluntad consensuada de los pintores e intelectuales de la época y que ayudaran a los primeros en su lucha judicial contra la Real Hacienda.

\footnotetext{
20 SigüEnZA, J.: Tercera parte de la Historia de la Orden de San Gerónimo. Madrid, 1605.

21 AHPM Protocolo 2188 fl. 1372 y Protocolo 2269 fol. 1095 a 1106.

22 JÁuregui, J. de: Rimas. Lyra Varreto, Sevilla, 1618.

23 Butrón, J. de: Discursos Discursos apologéticos en los que se defiende la ingenuidad de la pintura, Madrid, 1626.

${ }^{24}$ Butrón, J. de: Epistola dirigida al Rey suplicando protección para la Academia de los pintores, Madrid, 1626.

${ }_{25}$ Cervelló Grande, J. M.: Gaspar Gutiérrez de los Ríos y su "Noticia general para la estimación de las artes. Fundación de Apoyo a la Historia del Arte Hispánico. Madrid, 2006.

${ }^{26}$ VAnderhamen y León, L.: "Dicho y deposición". CARDUcho: op. cit.: pp. 421-428.

27 Vega CARPIO, L.: "Dicho y deposición”. Ibid., pp. 371-378.
} 
La voracidad impositiva justificó una pluralidad de ocasiones en las que los pintores tuvieron necesidad de defenderse, como se desprende de la cita contenida en el escrito de Butrón Por los pintores y su exempción, que Vicente Carducho incluye en su obra Diálogos de la Pintura ${ }^{28}$, en la que se recoge cómo una segunda exigencia del impuesto motivó el que tuvieran que probar, por segunda vez, la exención, reiterando un resumen del memorial jurídico confeccionado en 1627 , con el que, al parecer, la exigibilidad del impuesto se contrarrestó.

Tampoco ésta sería la última vez, porque la misma exigencia tributaria se suscitó, al menos, en otras dos ocasiones más. El tercer requerimiento lo recibieron los pintores por un Auto de 26 de mayo de 1636, firmado por el Contador Gabriel Pérez de Carrión, Juez para la administración de las alcabalas de la Concesión de Millones de la villa de Madrid y lugares de sus partidos, por el que se ordenaba al Alguacil de su comisión que requiriera y apremiara a todos los pintores de la villa de Madrid, que tuvieran una antigüedad superior a un año en el ejercicio de su profesión, para que manifestaran lo que habian vendido y que se les cobrara la alcavala sobre lo que habían vendido y cobrado de sus pinturas, afirmando que ello era conforme lo dispuesto y mandado por su Magestad por convenir asi a su servicio y cobro de su Real Hacienda ${ }^{29}$.

En cumplimiento de lo ordenado, sólo algunos de los pintores de Madrid hicieron sus declaraciones de ingresos o exhibieron los libros de venta por donde desian contavan las pinturas que abian bendido. Los demás se opusieron a ello, negándose a la exhibición de los libros y a dar razón del importe de las ventas.

Por este motivo, el Contador Gabriel Pérez de Carrión, al no poder establecer el montante de las ventas efectuadas por los pintores en sus casas y en sus tiendas, mandó investigar las operaciones realizadas por éstos y como resultado de estas investigaciones, el día 21 de junio siguiente, proveyó un Auto por el que se determinaba la cantidad que se presuponía vendida por los pintores y el importe que por la nueva alcabala les correspondía satisfacer por los dos años inmediatamente anteriores de 1636 y $1637^{30}$ y ello sin perjuicio del más valor que se averiguare, ordenando librar mandamiento a Gaspar Pimentel, Alguacil de su Comisión, para que iniciara la ejecución en las personas y los bienes de los pintores que se incluía en la relación. En cumplimiento de lo ordenado, el 26 de junio de 1638, dictó el requerimiento de pago de las nuevas alcabalas, relacionándose las personas sujetas al pago y los importes exigidos.

Lo interesante de estas imputaciones de pago es que nos proporcionan una perfecta información sobre el volumen de las ventas de los pintores en esos años y, por lo tanto, de su cotización y estimación social, así como los lugares de emplazamiento de sus talleres o de sus casas.

La relación contenía, como radicantes en la calle Mayor, a Francisco Barreda y a Simón Fuegos a quienes, por los dos años, se le fija como cantidad a satisfacer por el pago de impuestos correspondientes a sus ventas un total de 800 reales, a Xristobal de Eras, Juan de la Fuente y Joseph Leonardo un total de 400 reales por el mismo periodo, a Antonio Binzano 200 reales y a Julián Gonçalez 120 reales. En la calle de Toledo se relaciona a Domingo Carrión con la suma de 400 reales y a Cornelio de Ber, Domingo Guerra y Francisco Gascón con la suma de 200 reales. En la calle Albarquillo se cita a Joan de la Corte con la suma de 800 reales y en la calle de la Ve m. ${ }^{a}$ a Francisco Gómez con la suma de 400 reales. En el lugar frente a San Francisco se relaciona a Gerónimo Marquez con la suma de 400 reales y en la Salida de la red de San Luis a Francisco Bergel y a Angelo Leonardo con la suma de 400 reales. En Los Ángeles se cita a Domingo Yaguas con la suma de 120 reales. Por último se relacionaba a los Pintores de su $\mathrm{Mg}^{d}$ con las siguientes obligaciones de pago:

\footnotetext{
28 Butrón, J. de: “Información en derecho”. Ibid., p. 459.

29 AHPM: Protocolo 11550, folios 429 y ss.; GÁlleGo, J.: El pintor de artesano a artista". Universidad de Granada, 1976, pp. 252 y ss.

${ }^{30}$ Ibid., fl. 429.
} 
-De Diego Belazquez pintor de su magestad quatrocientos reales por dicho tiempo V. 400

- De Angelo Nardi otro tanto por el dicho tiempo V. 400

- De Vicencio Carducho otro tanto por el mismo tiempo V. $400^{31}$

Los pintores volvieron a recurrir el mandamiento de execución ante los señores del Consejo de Hacienda, por las cuantías en él referidas, estimándose de nuevo agraviados en su arte.

Encabeza la defensa de los intereses de los pintores en esta ocasión, Angelo Nardi, como Pintor de su Magestad, quien por sí y por los demás pintores de la Corte apeló, solicitando la nulidad de los autos y procedimientos referidos para el cobro de la alcavala de los questaban esentos por leyes y previlexios de pagarla, y que se cumplieran las ejecutorias reales que se habían dictado cuando los pintores habían litigado anteriormente con el Fiscal del Rey y por las que se había determinado que los pintores no debían pagar las alcabalas de cualquier género de pinturas que hicieren o vendieren ${ }^{32}$.

En esta demanda, Angelo Nardi defendió que los pintores no debían pagar alcabala de cualquier pintura que hicieren o vendieren, fundamentalmente, porque las pinturas que mis partes azen para vender por disposicion de derecho no se tiene por mercaderia sujeta apagar alcavala porque en ella obra más el entendimiento que las manos y asi se distingue en la dicha executoria que no se paga alcavala de las pinturas que los pintores hacen y venden y que sólo sepague de las que benden no haciendolas porque entonces llega a ser mercaduria.

En esta ocasión, el argumento esgrimido por los pintores para defender la exención del pago del impuesto fue que, al intervenir la inteligencia en la ejecución de la pintura, no podía ser ésta considerada como mercadería y que, por ello, sólo podía gravarse a la compraventa de pinturas realizadas por los comerciantes.

Ante el Fiscal del Consejo, Don Joan de Balboa Mogrobejo, acudieron con igual demanda Vicente Carducho, Eugenio Caxés, pintores del Rey, Bartolomé de Cárdenas, Pedro de Cardona, Joan de la Cortera, Antonio Monrreal y Pedro Núñez representados por Lucas de Ávila Quintanilla, su Procurador, y Lorenzo de Biana, Manuel de Molina, Diego de Salazar, todos ellos pintores de la Corte, por sí y en representación de los demás pintores, y Simón Fuegos, tratante en pinturas, quien el 27 de agosto de 1625 sostenía, por el contrario, que, a pesar de haber oído que los pintores mantenían que las pinturas de ruinas y de santos no pagaban alcabalas, éstas no gozaban de exención alguna, por lo que entendía que estaban sujetas al pago de las alcabalas por el encabezamiento que corría ${ }^{33}$.

El 29 de junio de 1626, respondiendo a la demanda del Fiscal, los pintores insistieron en que se les debía absolver y darles por libres de dicha demanda. Su petición fue un completo alegato de las razones que, a lo largo de los años, habían sido esgrimidas por los pintores y se concretaban en la siguiente forma "... porque dicho arte dela pintura es liberal y el más cientifico de las demas artes, pues en el se incluien todas y así los antiguos lo rrecivieron en el primer grado de ellos y como arte tan noble mandaron nose enseñase a asclavos ni jente baxa. Lo otro porque desde su primer principio hasido noble y como tal lan profesado y profesan muchos Reyes, principes y Señores que su exercicio loan tenido birtud yngeniossa por ser ymitadores de la naturalesa. Lo otro porque desde su principio y orixen deste dicho arte asido libre y esento de pagar alcavalas, pechos $n i$ derechos ni otras contribuciones, ni nunca lo an pagado, lo otro porque siendo esto asi siempre seles aguardado a los dichos pintores estas preeminencias las quales son tan antiguas que desde el tiempo de los emperadores Romanos augusto y Graciano y otros ycieron mandato expreso en el que los printores no fuesen enpadronados en ninguna encavecamiento de alcavlas ni otros tributoss y echos ni de derechos ni se ubiesen obligados a rrexistrar esclavos en el rexistro centual ni que

31 Ibid., fl. 437.

${ }^{32}$ Ibid., fls. 438-440.

33 Ibid., fl. 442. 
fuesen llamadoss para la collacion ni contribución de los tratantes y negociadores y que pudiersen tener en lugares publicos sus tiendas y obradores sin pagar alquiler ni que se les pudiese echar guespedes y otras muchas excepciones y libertades y questas se les guardase so grandes penas y que incurriran en la de los sacrilexios. Lo otro porque siendo esto asi que a los dichos pintoress desde tan largo tiempo se les an guardado estas presminencias no es justo que estando en estoss Reynos tan en su punto el dicho arte y aviendole ynlustado su magestad que guarde Dios mill años con su exercicio sea bituperado con esta contravencion. Lo otro, por que quando no constase delo dicho siendo triunfo personal de tanta ciencia y estudio y que se compone en una cossa de tan poca sustancia y balor como es un poco de tienzo y sólo se le da del estudio y maestria del artifice no deve pagar la dicha alcavala pues en los oficios mecanicos de lo que es trabaxo personal no se a pagado, lo otro porque por gocar esta preheminencia y noblesa muchas personas estudian y an estudiado el dicho arte y sean echo insignes, por lo qual an sido estimados en las rrepublicas de los Principes y señores de ellas lo qual no aran si se les encargasse este pecho porque nadie querría estudiar en el dicho arte y se bendría a perder cossa tan insigne y nezesaria en los Reynos ${ }^{34}$.

Ante esta alegación, el Fiscal solicitó que se informara acerca del tratamiento tributario que habían tenido las pinturas con anterioridad, informando el Escribano de Rentas Jerónimo Félix, el 10 de noviembre de 1626, que cualquier imagen de retratos y pinturas, tanto en papel como en tabla o lienzo y de cualquier género en que estuvieran hechas y las esculturas de bulto en madera, piedras o metales preciosos, y de cualquier cosa que viniera de Flandes estaban exentas del pago de alcabala.

En otro traslado, los pintores insistieron ser libres de pagar alcabala, reiterando las anteriores alegaciones y presentando una nueva, relativa a la naturaleza jurídica del contrato celebrado entre pintor y comitente, al que califican de innominado, porque lo que vendían y hacían era acomodar el yngenio y arte a la cossa que se trata de pintar lo que no se podía considerarse venta, sino un contrato ynominado por el que no se debía pagar alcabala, ni otro derecho.

El Consejo de Hacienda, el 13 de noviembre de 1630, dictó en Madrid sentencia en el pleito de Eugenio Caxés, estimando sólo en parte la demanda y declarando a los pintores libres de pagar la alcavala de las pinturas que hiciesen por concierto y conbeniencia con qualquier personass de la qual las declaramoss por libres y condenaban a los mismos pintores a pagar el Alcavala de las pinturas que hicieren para bender y futuramente debieren a razon de diez uno conforme a las leyes del Reyno y Ayuntamientos del cuaderno de alcavalas y por esta de nuestra sentencia ad finitum ${ }^{35}$.

No satisfechos con ello los pintores al no haber sido acogidas la totalidad de sus pretensiones, representados por su Procurador y defendidos por el Jurisconsulto Juan de Butrón, apelaron la sentencia solicitando que se les absolviera también de pagar sobre las pinturas que, ya ejecutadas, vendiesen y no sólo de las que ejecutasen por previo encargo, dado que era costumbre desde tiempo inmemorial no pagar alcabala, pecho o cualquier otro tributo por este hecho y porque el derecho de cobro del impuesto correspondiente a las pinturas que vendieran por compraventa, habría prescrito y apelando, por último, a la nobleza del arte de la pintura.

El Consejo, cambiando de criterio y haciéndose eco de la recomendación real, se pronunció de manera definitiva en el pleito promovido por Carducho, el 11 de enero de 1633, declarando que los dichos Pintores no paguen alcavalas de las pinturas que ellos hizieren y vendieren, aunque no se las ayan mandado hazer; y con que se aya de pagar alcavalas de las que vendieren no hechas por ellos en sus casas, almonedas y otras partes. "36

En el pleito de Caxés, el Consejo se pronunció también de manera definitiva el 13 de enero de 1633 , declarando al igual que en el primero de los pleitos que debemos absolver y absolvemos a los

\footnotetext{
${ }^{34}$ Ibid., fls. 443-444.

35 Ibid., fls. 449-450.

36 CARDUChO, op. cit: p. 220.
} 
dichos pintores de la demanda puesta por el dicho fiscal de su magestad en quanto a la alcavala de las pinturas que hicieren por el concierto y conveniencia de las pinturas que hicieren por concierto y conbeniencia con qualquier personas de la qual las declaramos por libres y condenamos a los dichos pintores a que paguen el Alcavala de las pinturas que hicieren para bender y efectivamente debieren a razón de diez uno conforme a las leyes del Reyno y ayuntamientos del cuaderno de alcavalas y por esta de nuestra sentencia definitiva así lo pronunciamos y mandamos ${ }^{37}$.

Sin embargo la revocación del pronunciamiento en el pleito de Carducho alcanzó después a este proceso, con lo que los pintores consiguieron que quedaran sin efecto las reclamaciones por pago de alcabalas correspondientes a la creación y compraventas de pinturas y que habían venido siendo exigidas durante la tramitación del proceso.

Poco duró la tranquilidad de los pintores, porque el 25 de octubre de 1638, los regidores del uno por ciento, volvieron a exigir a los pintores el pago global de 93.333 maravedís $^{38}$ por el concepto de la alcabala, orden que fue de nuevo recurrida por los pintores y que posteriormente fue resuelta a su favor por sentencia dictada por el Consejo de Hacienda el 3 de julio de $1640^{39}$.

Años después, el 30 de abril de 1696, Francisco Ronquillo y Brizeño, Caballero de la Orden de Calatrava, del Consejo y Contaduría Mayor de la Hacienda de su Majestad y Corregidor de la villa de Madrid encabezó un repartimiento de alcabalas, tercias y quatro medios por ciento que corrían a cargo de Madrid y sus Gremios, compareciendo la totalidad de los Alcaldes de los Gremios de la Villa que contribuían a los referidos derechos, determinando las cantidades a pagar a los tesoreros y del que tomaron encabezamiento todos los Gremios por las alcavalas, tercias, primero, segundo tercero y quatro medios por ciento desde 1697 en adelante, por un total de nueve años, hasta 1705 y se autorizaba a éstos a cobrar de sus afiliados las cantidades correspondientes a cada uno de ellos ${ }^{40}$.

En este encabezamiento ya no comparece el Gremio de Pintores, por no considerarles sujetos al impuesto, pero es indudable que el propósito de Antonio Palomino, cuando compareció ante el Escribano Juan Mazón de Benavides, el 4 de septiembre de 1696, solicitando que se recibiese información para que se declarara la autenticidad de la firma del escribano Manuel de Robles en el testimonio que éste había dado sobre los pleitos promovidos por los pintores Vicente Carducho y Eugenio Caxés y las sentencias recaídas en $\operatorname{ellos}^{41}$, no fue otro que el estar preparado, como representante del Gremio de los Pintores, ante cualquier otra reclamación que se les realizara por el pago de alcabalas.

Parece ser que, después de todos estos intentos recaudatorios y las sucesivas litis promovidas para la exención de tributos, la Hacienda de su Majestad dejó tranquilos a los pintores y no volvieron a exigirles impuestos.

Su victoria no sólo supuso el reconocimiento de exención impositiva, sino que consiguió, gracias a la férrea y constante defensa utilizada, el reconocimiento del prestigio de su oficio y la estimación social de su arte, apartándose definitivamente de los oficios agremiados y quedando asimilados a las demás artes liberales.

¡Los pintores habían ganado la batalla!

Fecha de recepción: 3-II-2008

Fecha de aceptación: 2-XI-2008

\footnotetext{
37 AHPM, op. cit. nota 28: fols. 452-453.

38 Ibid., fols. 459.

39 Ibid., fols. 461-462.

${ }^{40}$ Ibid., fls. 252-260 vto.

41 Ibid., fls. 429-433.
} 